\title{
La agroexportación como factor explicativo del mal desarrollo: La situación ecológica de El Salvador (1950-1979)
}

\author{
Poberto Rubio
}

\section{Introducción}

Valorar las incidencias de la que aún sigue siendo la principal actividad productora de bienes de El Salvador, es decir la agroexportación (aunque ha dejado de ser el eje articulador de la economia y la principal fuente de divisas)', sobre el desarrollo de la sociedad salvadorefna, depende en buena medida de lo que se entiende por desarrollo. Si ésle se limita al simple crecimienlo del PIB, la evaluación hislórica de la agroexportación (Agx.) no resulta tan negaliva. Por ejemplo, los relativamente altos niveles de precio de los productos de la Agx., y el sustancioso ingreso de divisas que ello representaba, fueron importantes variables que contribuyeron al elevado crecimiento económico experimentado después de la segunda guerra hasta tinales de los anos 70 .

En este trabajo pretendemos hacer una valoración de la Agx. tomando en cuenta otros criterios del desarrollo. Tomaremos como referencia sólo dos criterios o condiciones mínimas que nos parecen fundamentales

1. Por agroexportación entendemos un conjunto de actividades/relaciones socio-económicas que se implican y derivan de la producción, distribución y consumo de los llamados cultivos/productos tradicionales de exportación (café, caña de azúcar, algodón). 
en lodo proceso de desarrollo. ${ }^{2}$ La primera de ellas, de contenido más cuantitativo, hace mención a la necesidad de llevar a cabo una dinámica de crecimiento económico y de acumulación de forma constante y equilibrada. Sin un cierto incremento constante de la capacidad productiva, sin cierta oferta de bienes y servicios, sin ciertos equilibrios entre las variables macroeconómicas es difícil obtener un desarrollo adecuado. La segunda, de contenidos más cualitativos, atan̂e a las posibilidades/capacidades de mejorar la calidad de vida de las presentes y futuras generaciones. Si los incrementos de la capacidad productiva, si los bienes y servicios que se crean, si los equilibrios que se establecen no contribuyen a mejorar la calidad de vida de los pueblos, lejos estamos de aproximamos a un verdadero proceso de desarrollo. Este no puede surgir si no se salisfacen de forma suficiente y calificada las necesidades básicas de las mayorias, si no se eleva la calidad de las formas de vida de las presentes generaciones y si no se le garantiza a las luluras por medio del respeto al ecosistema, si los pueblos no son geslores crealivos y efectivos de su propio destino, etc.

Nuestras indagaciones nos permiten adelantar la hipólesis que lal como se llevó a cabo la Agx. en nuestro pais, al no contribuir o impedir la geslación de esas condiciones mínimas, ésta se constituye en importanle lactor explicalivo, entre otros, del mal-desarrollo que ha caracterizado históricamente la sociedad salvadoreña. Expresión de ello son los efeclos negalivos que la dinámica agroexportadora ha tenido sobre un componente fundamental de aquellas condiciones mínimas del desarrollo: la siluación ecológica de El Salvador.

La situación medio ambiental o ecológica es un lactor delerminante del desarrollo de los pueblos. En primer lugar, porque los desequilibrios del ecosistema constituyen un problema que concierne a todos; no es sólo un problema de desarrollo regional o nacional, es un asunto que compromete el desarrollo de los pueblos a nivel planetario. La deslorestación del Amazonas, la desertilicación del Sahel, la conlaminación del mar Mediterráneo y la "lluvia ácida" de la vieja Europa, los residuos nucleares, no son problemas localizados que afeclan solamente a brasilenos, nor-africanos, europeos del sur y del norte, y a los países con polencial nuclear, sino que es una problemálica que implica a lodos los ciudadanos del mundo y a sus futuras generaciones.(!gracias a los

2. Una delimitación más complela de nuestra noción de desarrollo se encuentra en el trabajo de tesis que sirve de base a este documento, a saber: Rubio Roberto "El rol de la agroexportación en la conformación del estilo de desarrollo, de la industria manufacturera, de la situación alimentaria y ecológica de EI Salvador". Tesis Doctoral en Estudios del Desarrollo. Universidad Católica de Louvain, Louvain-la-Neuve, Bélgica, 1991. 
desequilirios del ecosistema provocados por la modernización podernos al tin darnos cuenta que la interdependencia, tan de moda hoy en día, no sólo es un fenómeno socio-económico sino lambién lísico!. Que cada quien extraiga las consecuencias filosólicas, socio-económica y técnicas que se derivan de ello).

En segundo lugar, la relevancia de la ecología para el desarrollo se expresa a nivel del mismo proceso de crecimiento y acumulación. No puede haber un crecimiento y acumulación constante y equilibrado cuando los desequilibrios del ecosistema llevan a: disminuir la tertilidad del suelo y la "produclividad" de mares, lagos y ríos; provocar inestabilidades en la oferla y distribución de bienes agropecuarios a causa de los cambios climáticos; incrementar los "costos sociales" ocasionados por las "externalidades" de la modernidad industrial; elevar el monto de lo que podríamos denominar gaslos estériles, es decir los desembolsos o inversiones, normalmente del Eslado, empleados en los cuidados de salud y reparación de danos causados por el deterioro del ecosislema y/o la contaminación, etc. Es más, todos estos problemas socio-económicos derivados de los desequilibrios del ecosislema afectan negalivamente, a corto y sobre todo a medio y largo plazo, al mismo proceso de acumulación capitalista. Por ello, no es casual que se haya comenzado a hablar del "capitalismo verde"; ni que la ex-primera ministra Thatcher en Inglaterra, más allá de los intereses electorales que tuvo como trastondo, se convirtiera en supuesta delensora del ecologismo; ni que el Presidente Agnelli de Fiat postule la necesidad de arrebatarle la "bandera verde" a la izquierda europea; ni que el tema principal de la reunión anual de Davos (Suiza) hace tres anos, que convoca los más importantes empresarios y pensadores del capitalismo industrializado, haya tratado sobre el ecologismo.

En tercer lugar, los problemas ecológicos tienen una importancia directa con el logro de uno de los principales objetivos del desarrollo: la satisfacción de las necesidades básicas y la mejora de la calidad de vida de las mayorias. En efecto, los que más suelen padecer las consecuencias del delerioro del medio ambiente, son los sectores más desfavorecidos y desprotegidos. Es decir, todos aquellos que dependen de las frágiles y pequenas explotaciones agropecuarias, los que no tienen acceso a agua potable, los que no tienen más remedio que vivir en los suburbios cercanos a los complejos industriales, o los que se ven constrenidos a construir sus chabolas en barrancos expueslos a desbordamiento de ríos y tierra o inundaciones, los que no lienen posibilidades de comprar alimentos prolegidos, aquellos para los que la caza y la recolección de frulos juega un papel importanle en su dieta, elc. Tal pareciera que los pobres del mundo estuvieran condenados a conforman el gran 
vertedero del planeta, hacia donde convergen la mayor parte de sus calamidades sociales, económicas y naturales.

En referencia a este punto es de trascendencia destacar la indisociable y estrecha relación que existe entre desequilibrio del ecosistema y alimentación. Esto es mucho más pertinenle a la situación de los palses no industrializados. En éstos, siendo los desequilibrios ecológicos no sólo el resultado de "la riqueza producida por la modernización" sino también, y sobre todo, de la pobreza engendrada por la misma, los electos de los desequilibrios no sólo se hacen sentir en la calidad sino también en la cantidad de los bienes alimenticios. El delerioro ecológico de los países pobres es otra causa directa que explica sus estados de insuliciencia alimentaria. En esle sentido podria hablarse de una "ecologia de la pobreza".

En síntesis, en este trabajo se pretende evaluar el rol que ha tenido la Agx. en la conformación de la siluación ecológica de El Salvador (hasta 1979). En la primera parte se tralará de describir, con la ayuda de diversos indicadores, el estado de dicha situación. En la segunda parte estableceremos la relación existente entre el delerioro del ecosislema y el desarrollo. En la tercera parte se hará una somera evaluación del papel que ha jugado la Agx. en la conlormación de aquella situación.

\section{La situación ecológica de El Salvador.}

El calificar de calastrófica la situación medio-ambienlal de El Salvador no es gratuito. Según una de las investigaciones que hemos tomado de base para la realización de este punto, y que es resultado de misiones oficiales, "El Salvador es el único pais continental del hemisfério occidental y una de las raras naciones del mundo que han padecido una pérdida tan importante de recursos biológicos." ${ }^{13}$ El otro documento oficial en que nos hemos apoyado afirmaría lambién que "El Salvador es el pais con mayor degradación ecológica en el Continente Americano"."

Los desequilibrios del ecosistema salvadoreno no son exclusivos de los últimos anos. Las indagaciones históricas de una investigación llevada a cabo por una misión canadiense-salvadorena, da cuenta de algunos faclores que desde la época colonial (por el 1800) alectaron el ecosis-

3. DOUGGHERTY H.E, JEANNERET C.A y FLETCHER, Stratégies d'ecodeveloppement pour le Salvador, fotocopia, p.93, Ginebra 1989.

4. VARIOS EXPERTOS SALVADORENNOS Y AGENCIA PARA EL DESARROLLO INTERNACIONAL DE LOS ESTADOS UNIDOS DE AMERICA, U.S.A.I.D, Contrato 519-0167-C-00-2039-00, San Salvador, abril, 1985, p.22. 
tema del pais: la introducción de razas de animales espanoles que llevaron al uso de tierras para pastoreo, las exigencias del excesivo cultivo de exportación del anil, la demanda suplementaria de madera; elementos lodos ellos que dafiaron las extensiones de los bosques originales. A tal punto que eslos factores, junto con el desarrollo de otros cullivos comerciales, en especial la caña de azúcar, condujeron a que El Salvador, anlaño cubierto casi totalmenle de bosques, hacia 1900 sólo dispusiera de un $10 \%$ de su superficie con una cubierta torestal primaria. A propósito de la erosión del suelo, dicha misión reportaría que "Se trata sin embargo de un fenómeno observado desde hace decenios. Por ejemplo, Standley (1924. N. del A.) ha descrito la intensidad de la erosión de los suelos salvadoreños a principios de los años $20^{\prime}$; y continúa diciendo " $E n$ un estudio sobre la conservación realizado en 1946, la erosión del suelo era descrita como el más serio problema agricola y económico que haya jamás encontrado la República salvadorena". ${ }^{5}$

Trataremos ahora de describir la gravedad de la siluación a través del análisis de algunos componentes del ecosistema de El Salvador: la tierra, el aire, la vegetación, los recursos acuíferos y las especies anima-

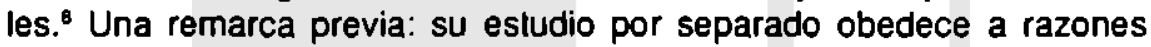
ilustrativas y no a consideraciones leórico-analíticas. Todos esos componentes son inseparables, se inlerelacionan y se afectan muluamenle. El ecosistema es uno solo.

i. Respecto a los suelos. Ya para 1974 el $77 \%$ de la supercifie tolal del pais se encontraba seriamente afeclada por la erosión. Los problemas son particularmente graves en la zona norte del país. Acá la erosión abarca casi la tolalidad de las tierras, "La capa arable del suelo, habiendo casi completamente desaparecido, esta región presenta actualmente un suelo rocoso, improductivo, cubierto de chaparrales $y$, en ciertos casos, completamente desnudo" (Dougherty y otros).

Los problemas de la erosión se verán también reflejados dentro de las dificullades que se presentan a nivel de la vegetación. Además, los desequilibrios a nivel del recurso suelo no se relieren únicamente al fenómeno de la erosión sino también al de la contaminación. Aunque quizá de menor envergadura, la contaminación de los suelos es un aspecto relevante del ecosistema salvadoreno. Estos se vieron afeclados, en primer lugar, por una contaminación de residuos domésticos. Los suelos interiores y circundantes de las ciudades son los más danados, sobre todo cuando tomamos en cuenta que sólo la ciudad capital disponía de

5. DOUGHERTY Y OTROS, Op. cit., p. 43 y 44.

6. La mayorla de las intormaciones fueron tomadas de las dos obras anteriores. 
"rellenos sanitarios" para los depósilos de basura y que en éstos sólo se deposita el $70 \%$ de los desechos doméslicos (1o que significa que en la ciudad de San Salvador quedaban sin recoger o eran depositados en superficies no determinadas, cerca de 120 loneladas de basura al dia). Una segunda fuente de contaminación son los residuos industriales. A pesar de la existencia de rellenos sanitarios y de los mayores registros sobre la cantidad de basura, valga indicar que la contaminación de los suelos por la industria no proviene tanto de los cuerpos sólidos depositados en los rellenos como basura, sino de los desechos que de forma liquida van a parar a los rios circundantes. Eslo es especialmente válido para la agroindustria : beneficios de café, ingenios azucareros, benelicios de maguey y kenaf, destilerias, induslrias lácteas y texlileras, rastros. La tercera y más importante causa de contaminación de los suelos es la que proviene de los vertidos agrícolas, o del uso de pesticidas, herbicidas, fungicidas; los cuales más allá de sus consecuencias nocivas sobre el consumo y la salud humana, pueden incidir negativamenle en la composición y productividad de los suelos.

ii. En cuanto a la calidad del aire. Los trabajos consultados senalan que el problema de la contaminación del aire es muy serio en El Salvador, pero anotan la lalla de estudios al respecto. Algunos dalos generales indican que los problemas de contaminación del aire eslán particularmente presentes en la ciudad capilal, donde en 1981 se concentraba más del $63 \%$ del parque de aulomóviles y se daba la mayor densidad poblacional e industrial. Los grados de contaminación del aire en la ciudad de San Salvador se agravan con la tradicional quema de parte de las basuras que no son depositadas en los rellenos sanitarios, y en los afios ochenta con la llegada de muchos desplazados a causa de la guerra y la falta de servicios sanitarios. Esta carencia de servicios en época seca expone las excrelas al fuerle sol y viento y se convierte en imporlante luente de transmisión aérea de microrganismos y enfermedades.

Hay que indicar sin embargo que, a pesar de la existencia de cierta capacidad y diversidad induslrial, no habia presencia masiva de industria que podria considerarse de alto riesgo para la contaminación atmostérica. Obviamente habia sus excepciones, como las dos tábricas de cemento en el Occidente del país, la gran refinería del puerto de Acajulla y la planta de producción de ácido sultúrico, también ubicada en la misma región. La ciudad capital parecia entonces no disponer de muchas indusIrias con emisiones de allo riesgo. Desgraciadamente, el pais no dispone de muchos medios para llevar a cabo un control de los grados de contaminación almosférica. Sólo podemos encontrar una inslalación en el medio rural del Occidenle del país (en el Cerro Verde) y constatar la existencia de un programa de control y muestreo de contaminación atmosté- 
rica por parte de la División de Saneamienlo Ambiental del Ministerio de Salud. Ambos fueron creados solamente hasla la primera década de los 70.

iii. El estado de los recursos forestales. Hace mucho tiempo atrás más del $90 \%$ de la superticie del país se encontraba originalmente cubierta de bosques. Sin embargo, diversos factores, que estudiaremos más adelante, han contribuido a convertir a El Salvador en el pals del conlinente americano que posee el menor porcentaje de áreas naturales. En efecto, ya para fines de los 70 fuenles oficiales u oficiosas atirmaban que más del $80 \%$ de la vegetación nalural del pais habia sido eliminada en su totalidad, y que no se habían podido conservar más que 20000 hecláreas de bosque primitivo, es decir únicamente cerca del $1 \%$ de su vegetación originaria. Olras fuentes hablan del $6 \%$. Asi, en el paisaje de El Salvador sólo podlamos enconlrar unos cuantos raros y amenazados remanentes boscosos de importancia: el bosque nebuloso de Montecristo en la zona norte de tierras altas, el parque nacional Deninger en las tierras bajas del cenlro, y los bosques de Nancuchiname y El Imposible, on las tierras del sur Oriente y sur Occidente del país.

Acorde al tipo de clima y/o altura sobre el nivel del mar, la situación forestal se presentaria de la siguiente manera:

iii.1. De los bosques nebulosos (arriba de los $1800 \mathrm{~m} / \mathrm{s}$.) sólo quedarían apenas unas $2500 \mathrm{Ha}$. Como constataría uno de nuestros estudios consultados "El hombre ha casi completamente destruido los bosques nebulosos que poblaban antes los volcanes de Santa Ana, San Salvador y San Vicente (centro-sur del pais) y la región de Los Esimiles, y com. prendido el bosque de El Pital que era el más extenso de El Salvador".? El penúllimo bosque nebuloso, el de Los Sisimiles, práclicamente se exlinguló hacia fines de los años 60 .

iii.2. Entre los 1800 y $1200 \mathrm{mls}$, los bosques de robles y encinos han sldo eliminados casi por complelo. Mientras que de los bosques de pinares se calcula que quedan sólo unas $3000 \mathrm{Ha}$.

iii.3. Los bosques entre los 100 y $1200 \mathrm{mis}$. han sido los más afeclados por el estilo de desarrollo experimentado en El Salvador. Del tolal de este tipo de bosques que cubrlan la mayor parte del territorio nacional (cerca de 1.1. millones de Ha. de vegetación original), apenas quedan unas $10000 \mathrm{Ha}$.

iii.4. Especial mención tienen los bosques que se encuentran a menos de $100 \mathrm{mts}$. de allura, normalmenle denominados manglares. Estos bos-

7. DOUGHERTY Y OTROS, op. cil., p.40. 
ques salados que han poblado gran parte de la costa salvadorefia, de gran valor económico, ecológico y biológico, a pesar de haber manteriido antes de 1950 unas $100000 \mathrm{Ha}$. de las 120000 originales (en parte gracias a lo inhóspilo para la vida humana), fueron rápidamente mermadas. Para fines de los años 70 no quedaban más que cerca de $3000 \mathrm{Ha}$. de mangles. Como lo constatáremos en el próximo punto, la expansión de la agroexportación, del algodón en particular, fue uno de los principales causantes de dicha degradación forestal.

Como consecuecia de todo el proceso de delorestación llevado a cabo por el tipo de desarrollo predominante en El Salvador, en este país cerca de 65 especies dilerentes de árboles se habian extinguido o estaban a punto o en peligro de extinción, y lo mismo ocurria con 61 especies de flores ( 53 de orquídeas y 8 de bromélias).

iv. Los recursos hidricos. Los problemas que presentan los recursos acuiferos en El Salvador poseen una gravedad tanto a nivel de cantidad como de calidad.

En buena medida debido a las dilicultades derivadas de la erosión del suelo, las disponibilidades de agua se han visto seriamente mermadas: "La rápida escorrentía, la disminuida capacidad de absorción y almacenamiento del agua pluvial en el suelo, la falta de reposición de los manantiales subterráneos, la mayor evaporación en la superticie (fenómenos todos ellos ligados a la erosión. N. del A.) y la creciente demanda de una población que se incrementa rápidamente, han producido en muchos lugares del país una grave escasez de agua."8 La investigación de la misión canadiense/salvadorefía concluiría al respecto que "El agua parece ser el recurso natural que impone las mayores dificultades al de. sarrollo socio-económico de El Salvador dada las actuales penurias y la demanda siempre creciente para la agricultura y el consumo urbano $e$ industrial." "Así, los trabajos antes mencionados, lomando los cálculos hechos por el Servicio Hidrológico Nacional, afirman que para 1990 se necesitarán 400 metros cúbicos por segundo (M3/s) para satisfacer la demanda sectorial y $580 \mathrm{M} 3 / \mathrm{s}$ para la dilución natural de los ríos contaminados. Mientras que la disponibilidad promedio a nivel nacional es sólo de $677 \mathrm{M} 3 / \mathrm{s}$, es decir que en 1990 se tendría un délicil, solamente para lales propósilos, de $303 \mathrm{M} 3 / \mathrm{s}$. Si se considera únicamente el abaslecimiento de agua potable, la problemálica adquiere mayores dimensiones ya que en 1979 , solamente el $66.8 \%$ de la población urbana y el $34.1 \%$ de la población rural disponian de agua polable. ${ }^{10}$

8. VARIOS EXPERTOS SALVADOREÑOS Y AID, op. cit., p.22.

9. DOUGHERTY Y OTROS, op. cit., p.90.

10. LOPEZ José y GALLARDO María, Centroamérica, la crisis en cifras, IICA 
Pero los desequilibrios de los recursos hídricos son también muy notorios a nivel de la calidad de las aguas. Como ya lo hemos mencionado, los lagos y ríos de El Salvador se encuentran enlre los más contaminados del mundo.

Los trabajos consultados deslacan el tenómeno de la eutroficación artificial o acelerada (el "envejecimiento nalural" de los cuerpos acuáticos) de la mayor parte de los lagos y lagunas del pais, originado por la fuerte y acelerada entrada de sedimentos naturales (por efecto de la gran erosión y/o deforestación existente) o artificiales (como las fuertes cantidades de fertilizantes, pesticidas, elc.). Varias perturbaciones en los sistemas acuáticos son frecuentes en los lagos y lagunas del país. Varias lagunas y lagos de agua dulce como la de Chalchuapa, El Jocotal, la de Olomega, la presa 5 de Noviembre y la del Cerrón Grande, y el lago de Guija, han sido invadidas, por razones aún desconocidas, por masas flotanles de algas que alectan negalivamente la pesca y la producción de energía. Por olro lado, las elevadas existencias de cangrejos que caraclerizaban el lago de Coatepeque han sido severamente dańadas: si en 1957 se estimaba que la extracción de esla especie comercialmente importante era de 2 millones de cangrejos anuales o sea unas 200 Ton. al ano, para 1979 dicha extracción era de apenas 38.6 Ton. ${ }^{11}$

En el caso del lago artificial del Cerrón Grande, que servia de luente alimenlicia para muchas comunidades que habitan sus alrededores (sea gracias a la pesca o al uso agropecuario de sus aguas), encontramos un alto nivel de contaminación. En este lago de reciente y controvertida lormación existe "un alta diversidad y cantidad de organismos patógenos, que generan alta incidencia de enfermedades endémicas y epidémicas en las comunidades alrededor de estos cuerpos de agua, y el alto riesgo de consumir los productos animales y vegetales derivados del cuerpo de agua en referencia, o del uso de sus aguas". ${ }^{12}$

La situación ecológica de los ríos parece ser más alarmanle. Por un lado, muchos rios y arroyos de pequena envergadura han venido presentando inestabilidades a nivel de sus caudales. En buena parte de ellos los caudales se han interrumpido durante la época seca, y en algunos arroyos, en particular del Oriente del pais, los caudales siguen siendo inestables incluso durante la estación lluviosa. Solo los ríos de mayor dimensión habian podido mantener caudales constantes. La rápida escorrentía ocasionada por la lala de árboles, la fuerte erosión y menor com-

FLACSO, San José, Cosla Rica, 1986, cuadros 6.3 y 6.4, p.215.

11. EXPERTOS SALVADOREÑOS Y AID, op. cit., p.101.

12. Ibid., p.4. 
pactaciòn de los suelos, son algunas de las variables que explican tales inestabilidades en el caudal de los ríos.

Por olro lado, la mayor parte de los ríos y arroyos de El Salvador se encuentran seriamente contaminados. Más allá del hecho que parte del origen de la contaminación de los rios se encuentre en los graves problemas de erosión (que lavorece el lavado de los residuos y su mayor afluencia hacia rios, lagos y mares), los principales contaminanles de los afluentes han sido los vertidos domésticos y los desechos agricolas y agroindustriales. Algunas muestras de la División de Saneamiento del Ministerio de Salud sobre la calidad sanilaria del agua superficial dan prueba de la conlaminación por vertidos domésticos: 1 . Todos los ríos de la importante cuenca del rio Lempa presentaban altas concentraciones de coliformes de origen fecal durante todo el año. 2. Los ríos Acelhuate y Suquiapa, que son portadores de las aguas servidas de las dos principales ciudades del pais, San Salvador y Sar'a Ana, presentaban concentraciones muy allas de coliformes fecales (mayores de 100000/100 ml). A pesar de la gravedad que presentan estas cilras para la salud humana y del conocimienlo oficial que se tiene de ello, no parecieron existir programas de protección de ríos y/o de tratamiento de aguas negras.

Los otros focos de contaminación de los ríos son los residuos agrícolas y agroindustriales. En cuanto a los primeros se destaca el uso de pesticidas en el cultivo del algodón. Sobre el punto creemos conveniente cilar lo siguiente: "Según Mckee y Wolf (1976), concentraciones de DDT de $0.1 \mathrm{mg} / \mathrm{tt}$ durante 12 horas consecutivas, son suficientes para matar todos los peces de un cuerpo de agua. En cuanto al Dieltrin, concentraciones de $0.125 \mathrm{mg} / \mathrm{lt}$., tienen el mismo efecto letal anterior. En el rio Grande de San Miguel se han encontrado concentraciones hasta de 3.15 mg/t de DDT y $3.77 \mathrm{mg} / \mathrm{lt}$. de Dieltrín...". ${ }^{13}$ Se encontraron también muchas cantidades de plaguicidas en las launas de los esteros pertenecientes a la Bahía de Jiquilisco.

Referente a los segundos señalemos que denlro de los residuos industriales, los residuos agroindustriales son los de mayor incidencia en la contaminación de los ríos en El Salvador. En efecto, los residuos provenientes del beneficiado del calé, del maguey y del kenaf, de los ingenios azucareros, de las indusiria lácteas, destilerías, y en menor medida de la industria textilera y papelera, son residuos de naturaleza orgánica. Su llegada a los cuerpos de agua demanda de éstos altas cantidades de oxigeno. Por ello no es casual que olro sintoma de la contaminación de los rios salvadorefios sean sus condiciones anoxicas, es decir su falta de

13. Ibid., p.153. 
oxigeno disuello. Los mismos muestreos de la División de Sanidad a los que hemos hecho alusión antes llegaron a delerminar lo siguiente: 1. En los ríos de la cuenca del principal río del pais, el Lempa, en época seca se encontraron cantidades de oxigeno disuelto inferiores al limite sanitario permisible, o sea menos de $4 \mathrm{mg} / \mathrm{tt}$. No es casualidad, sehalan las mismas fuentes oficiales, que estos valores críticos coincidan con la mayor actividad de los beneficios del calé y de los ingenios del azúcar. 2. Otros ríos o cuencas imporlantes presentaban casi ausencia de oxígeno disuelto en sus cuerpos de agua: el Suquiapa, el Acelhuale, cuenca del rio Paz, el río Sapuyo y los ríos de la región de la cuenca del río Grande de San Miguel (contaminada por residuos del procesado del maguey y el kenaf). La contaminación de los ríos Paz y Grande de San Miguel se veian agravados por el hecho de que el primero recibía los residuos que van al mar de la Central Geotérmica de Ahuachapán (residuos de altas temperaturas, concentración de sales y arsénico), mientras que el segundo caplaba los vertídos de la mina de San Sebastián.

El eslado ecológico del más grande e importante río de El Salvador, el Lempa (su cuenca abarca las dos lerceras partes del terrilorio nacional, comprende las principales regiones agricolas y es la principal fuente de energía hidroeléclrica), era también lamentable. Uno de nuestros estudios de referencia destaca: 1. Un proceso acelerado de eutroficación. 2. Prolileración de hierbas acuáticas. 3. Altos niveles de contaminación por pesticidas y otras sustancias quimicas nocivas 4 . Una importante modificación del "habitat" de los peces. 5. Multiplicación de condiciones que favorecen la proliferación de microrganismos portadores de enfermedades.

Las aguas subterráneas y los mares no se escapan tampoco de los altos niveles de conlaminación. Muchas de las primeras, que son fuente de consumo de gran parte de la población rural, poseen allas concentraciones de bactérias (sobre todo organismos coliformes de origen fecal) y de residuos quimicos. Muchos pozos del Oriente del país, como to han podido comprobar varias investigaciones oficiales, contienen aguas que pueden estimarse de fuertemente lóxicas. En cuanlo a los mares y/o aguas de playa, el Irabajo apoyado por la AID hace referencia a muestras tomadas por la Dirección de Recursos Nalurales Renovables de El Salvador. Eslas constalaban la lurbidez de las aguas del litoral cercanas a las desembocaduras de los ríos, incluso con penetraciones de varios kilómetros mar adentro; otras franjas costeras próximas a puertos o a vertederos presentaban concentraciones de colitormes que iban de $10 \mathrm{mil}$ a $100 \mathrm{mil} /$ por cada $100 \mathrm{ml}$.; se descubrió la presencia de ciertas algas, que como las filamentosas, pueden ser rellejo de la contaminación.

La situación de las especies animales se ha visto afeclada por varios 
factores. Uno de los más importantes de éstos proviene de los desesquilibrios en el ecosistema. No cabe duda que muchas especies animales han desaparecido por la eliminación de su habital vegetativo, por la desaparición de los bosques que les daban protección y alimento, o por la contaminación de las aguas y del aire. Dado que la eliminación de las especies animales es una de las principales consecuencias directas del deterioro de los recursos analizado anteriormenle, y por lanto será vista en el próximo punto, nos limilaremos a dar los "resultados generales" que, a este nivel, han lenido los años de vigencia e impulso del estilo de desarrollo agroexportador. Desde que va del presenle siglo, dentro del mapa zoológico de El Salvador han desaparecido (quizá para siempre) al menos 13 especies de vertebrados, otras 66 se encuentran en peligro de extinción, y 49 de ellas confrontan diversas amenazas de extinción.

Una vez descrito el estado de algunos de los recursos nalurales que conlorman el ecosislema salvadoreño, hemos creído conveniente, antes de pasar a ver el rol que la Agx. juega en ello. llevar a cabo un análisis sobre algunos de sus eleclos sobre el desarrollo del país.

\section{Los desequllibrios ecológlcos y sus impllcaclones para el desa- rrollo de El Salvador.}

1. Las implicaciones sobre la calidad de vida y la salisfacción de las necesidades básicas de las mayorias.

i. Los graves desequilibrios ecológicos que presenta El Salvador han empeorado aún más la calidad de vida de la mayor parte de salvadorehos. Los efectos más directos y visibles del desequilibrio del ecosistema se hacen sentir sobre la salud humana.

Los altos y generalizados niveles de contaminación que encontramos en los bienes alimenticios están estrechamente vinculados a la contaminación de suelos, agua y aire que caracterizan el ecosistema del pais. Pero resulta que los efectos nocivos para la salud del desequilibrio ecológico no se limitan sólo al consumo de alimentos. Asi por ejemplo, varias entermedades o muertes lienen su origen en el consumo directo de agua 0 aire conlaminado. Señalemos que una de las principales causas de la enlermedad más mortal del pais, es decir la gastroenterítis (asi como el parasitismo intestinal) es, junto con la desnulrición, el consumo de agua contaminada. No es casual tampoco que esta enfermedad haya estado más extendida en el medio rural, donde se carece mayoritariamente de agua polable. Ultimamente, las enfermedades respiratorias vienen conviertiéndose en una de las principales causas de muerte entre los ninos menores de cinco afios. 
Otras enfermedades eslán relacionadas con los desequilibrios ınismos que se dan a nivel de las especies. Así por ejemplo, la utilización masiva de insecticidas en el cultivo del algodón condujo a una suerte de "selección artificial de las especies entre los insectos". De lal forma que el desarrollo de una resistencia genética en el mosquito transmisor del paludismo (Anopheles), y la virtual eliminación de sus depredadadores naturales por parte de los insecticidas, hicieron resurgir el problema del paludismo en El Salvador. Hagamos notar que esta era una enfermedad que desde hace más de diez años se consideraba ya erradicada del pais, y que la Organización Mundial de la Salud (OMS) senalara nuevamente a El Salvador como un país de malaria endémica.

ii. Una consecuencia importante sobre la satistacción de las necesidades básicas y/o la calidad de vida de la mayoria de salvadorefios es la que alecta las posibilidades de enriquecimiento de la diela alimenticia. Es sabido que hace algunos años atrás buena parte de los habilanles rurales enriquecian su dieta básica con diversos alimentos, ricos en proteína de alta calidad, que encontraban en la vida silvestre : a través de la recolección en árboles frutales, de la caza de animales y de la pesca esporádica. La extinción o reducción de muchas especies ha dahado gravemente aquellas preciosas posibilidades. No hay duda, por ejemplo, que la dráslica reducción de los manglares (bosques marinos importantes para la reproducción de mariscos, aves y reptiles) y olra vegetación costera, asi como el uso masivo de produclos quimicos en la producción agricola, incidieran muy negalivamente en la dieta de los campesinos de la costa oriental de país. Esto debido a la casi desaparición o disminución de especies, que como la iguana, garrobo, "cusuco", "cascos de burro", etc., formaban parte no desdefiable de su diela.

iii. Además de la salud y la dieta, olro de los parámetros de la calidad de vida de las poblaciones humanas que se ha visto seriamente tocado es el que alahe al habilat de las mismas y sus implicaciones sobre los movimientos migratorios. Una de las principales causas de la baja densidad o cuasi-despoblamiento de la zona norte del pais y de la otrora migración de miles de salvadoreños hacia Honduras o hacia la ciudad capital, ha sido el extremo deterioro del ecosistema en esa parte del territorio. Los bajísimos niveles de productividad del suelo, los allos grados de erosión, la drástica reducción de las posibilidades de abastecimiento de maleriales o alimenlos de la vida silvestre, la fuerte merma de las reservas y abaslecimientos de agua, entre otros factores, han hecho de la zona norte una región baslante "inhabitable". 


\section{Las implicaclones sobre el logro de un proceso de crecimlerito/ acumulaclón sostenido y equillbrado.}

Los desequilibrios del ecosistema no tienen solamente implicaciones sobre la calidad y las formas de vida de las mayorias, sino también sobre el adecuado crecimiento económico y la ampliación de las capacidades productivas.

i. El despoblamiento de la zona norte, y la migración hacia la ciudad capilal que se desprendió de ello, constituyeron elementos que aumentaron las disparidades regionales y disminuyeron las posibilidades de obtener un crecimiento regional equilibrado.

ii. Los problemas ecológicos influyen negativamente en las disponibilidades de bienes agropecuarios, Ian necesarios para el sostenimiento del crecimiento económico y la acumulación (para la reproducción y productividad de la fuerza de trabajo, para la reducción de las importaciones o el aumento de las exporlaciones, o sea sobre las disponibilidades de divisas, en el abastecimienlo de maleria prima para la industria, etc.).

Las disponibilidades de bienes agropecuarios se vieron real y potencialmente disminuidas a causa de algunos de los desequilibrios ecológicos ya analizados:

ii.1. La producción agrícola ha sido afeclada a causa de la erosión y el uso generalizado de tertilizantes-peslicidas, y sus secuelas sobre la productividad de los suelos.

ii.2. La produción pesquera se ha visto lambién debilitada, en buena parte debido a la conlaminación de las aguas. La oblención de divisas a través del camarón presenta menores posibilidades, como lo patenliza el hecho que la pesca de tal producto de exportación se haya reducido a casi la mitad para fines de los años 70 si se le compara con lo obtenido antes de 1964.

ii.3. La práctica eliminación de la cubiena lorestal ha sido una de las importantes razones de la pérdida de gran parte de las disponibilidades alimenticias silvestres. La fuerte disminución de éstas no sólo concierne el consumo, la reproducción y la productividad de las masas trabajadoras sino también sus bolsillos (los precios de las frutas, por ejemplo, tendieron a hacerse más elevados). La pérdida de muchas especies vegetales, y con ellos de muchos agentes polinizadores, perjudica también la misma reproducción de las plantas y árboles.

ii.4. La menor producción forestal es una de las consecuencias lógicas de la grave pérdida de la cubierla de bosques. Eslo ha pesado sobre la disponibilidad de divisas a través de las mayores importaciones de 
madera: éslas, entre 1964 y 1976, signiticaron un saldo comercial desfavorable, en promedio, de más de 34 millones de colones por ano. ${ }^{14}$

ii.5. La escasez de agua representa menores márgenes para el incremento de la producción agrícola por medio de la expansión de la superficie bajo riego.

ii.6. Finalmente, el almacenamiento de los granos básicos se vió danado por la modificación de los necesarios equilibrios que deben existir entre las especies. De lal forma que el exterminio de los depredadores naturales de los roedores, como las culebras, sea uno de los motivos de su mayor y más Irecuente aparición, sobre todo en los lugares cercanos a los centros de almacenamiento de granos.

iii. Un aspecto interesante de analizar son los efectos de los desequilibrios del ecosislema sobre lo que podríamos denominar el "abanico de posibilidades lécnicas". La minimización de estas posibilidades, una de las "Yuerzas de apoyo mágicas" del capitalismo, se ve también estimulada por la misma degradación del medio ambiente que la modernización capitalisla produce. Pongamos dos ejemplos válidos para el caso salvadoreño. En primer lugar, la disminución de la fauna de insectos por parte del uso masivo e indiscriminado de insecticidas, más allá de favorecer el desarrollo de especies nocivas para la agricultura, signilica la pérdida de una fauna que podria ser utilizada en el control biológico de plagas. Esta "técnica suave" o allernativa ve por lanto estrechada su posibilidad de aplicación. Un segundo ejemplo : la "quimiquización" de los suelos normalmente suele entranar una pérdida importante de sus nutrientes nalurales... y el empobrecimienlo de la tierra hace una mayor demanda de fertilizantes. A mayor uso de lertilizantes, mayor pobreza del suelo o mayor necesidad de manlenimiento de sus niveles anteriores de produclividad. $Y$ a esla mayor necesidad corresponden aún mayores aplicaciones de fertilizantes. Nos encontramos asi en una siluación donde la mala técnica llama a la mala técnica. Un círculo vicioso que deja poco espacio a la aplicación de las "buenas técnicas".

iv. Por úlımo, los desequilibrios del ecosistema se traducen también en mayores cosios energéticos. La pérdida de caudales de buena parte de los rios del país, la contaminación o eutrolicación acelerada de represas hidroeléclricas como la del Cerrón Grande, la sedimentación rápida de muchas represas a causa de la erosión y la disminución de su "vida operativa" que provocan, son algunas de las manileslaciones que inciden negativamente en la capacidad actual y futura de producción de energía eléctrica. La posible aumentación de los coslos que de ello resulta tiene

14. Ibid.. p.58. 
efectos nocivos sobre la dinámica de las actividades económicas, en especial las industriales. Por otro lado, las menores disponibilidades de especies pueden signilicar también aumentos en los costos energélicos. Así, la disminución en las disponibilidades de camarón, a las que hemos hecho ya relerencia, no es un tenómeno ajeno al incremento en un $50 \%$ en la canlidad de combustible utilizado por barco pesquero, experimentado entre 1963 y $1972 .^{15}$

En resumen, la siluación ecológica de El Salvador no ha contribuido al desarrollo del país. Los desequilibrios en el ecosistema, en buena parle provocados por el estilo de desarrollo agroexportador (EDA) y/o la expansión de la agroexportación (como lo intentaremos mostrar en el próximo punto), trajeron consecuencias nefastas sobre la satisfacción de las necesidades básicas de las mayorías y en la mejora de la calidad de sus vidas. La salud, la dieta y el habitat de los salvadorenos se han visio negativamente implicados en ello. Asimismo, el deterioro del ecosistema, afectando los equilibrios regionales, la disponibilidad de bienes agropecuarios, el aprovechamiento del abanico de posibilidades técnicas, disminuyendo la capacidad de producción de energia o elevando sus costos, se ha convertido en un grave obstáculo al mantenimiento del crecimiento económico y la acumulación constanle y equilibrada.

Hasta acá hemos llegado a concluir que la situación ecológica de EI Salvador no ha sido laclor de desarrollo. Todo lo contrario, ha sido importante configurador de su estado de mal-desarrollo. Es por tanto el momenlo de pasar a evaluar el papel que ha tenido el EDA o la Agx. en la determinación de dicha situación.

\section{El papel de la dinámlca agroexportadora en la conformaclón de la situación ecológica de EI Salvador.}

En esta sección linal del trabajo intentaremos analizar de qué manera la Agx. ha contribuido a la gestación de la desastrosa situación ecológica que caracleriza El Salvador. Sin intención de agotarlas, hemos podido idenlificar varias causas que explican aquella crítica y alarmante situación.

Unas causas pertenecen más bien al funcionamienlo y expansión de la dinámica del capital agroexportador y hacen mención especial a los patrones lecnológicos que han predominado en ella: la implantación de un tipo de sistema productivo que denominaremos "modelo tecnológico especializado" (MTE), bajo el que funciona la dinámica agroexportadora.

15. DOUGHERTY Y OTROS, op. cit., p.6. 
Asimismo encontramos otra causa que hace referencia al tipo de terıencia y uso que al suelo otorga dicha dinámica.

Por otro lado, encontraremos factores explicalivos que aunque son más bien rasgos o componentes del estilo de desarrollo que ha predominado en El Salvador, vienen en buena medida determinados por la dinámica agroexportadora. Estos elementos se relieren a: A. La extrema pobreza. B. La polílica económica gubernamenlal.

1. Factores expllcatlvos que pertenecen al funclonamlento o a la expansión de la dinámica agroexportadora.

\subsection{La Implantación del Modelo Tecnológlco Especlalizado. ${ }^{16}$}

El que llamaremos Modelo Tecnológico Especializado (MTE) que caracteriza los sistemas productivos de la Agx., es una de las principales causas que explican la pésima siluación ecológica de El Salvador.

\subsubsection{El Modelo Tecnológico Especiallzado.}

La concepción de "modelo tecnológico especializado" la hemos adquirido del excelente Irabajo realizado por V.M. Toledo sobre la problemática ecológica y alimentaria en México." Como atirma este estudio " $\mathrm{Tal}$ modelo modifica las condiciones naturales con el objeto de implantar ecosistemas artificiales basados en una sola especie (monocultivos) y sobre superficies extensas, que se mantienen mediante grandes insumos energéticos y económicos (maquinaria, fertilizantes, plaguicidas, riego artificial, etc. $)^{n} .{ }^{18}$ En referencia al sub-sector agricola, la investigación mencionada sefiala algunas condiciones naturales que son convenientes a la puesta en marcha del MTE : "Existen por lo menos cuatro "ingredientes" ecológicos esenciales para que el modelo tecnológico especializado alcance a funcionar dentro de la producción agrícola: topografía plana, suelos fértiles, recursos de agua seguros o muy probables (buen temporal) y ciclos climáticos bien marcados (que atenúen la incidencia de plagas; a ello debe agregarse una superficie lo suficientemente extensa

16. Los análisis del MTE que siguen a continuación han sido retomados de otro de nuestros arliculos publicados por la Revista Realidad: RUBIO, Roberto "Incidencias de la política económica predominante en algunos parámetros de la seguridad alimentaria", Revista Realidad Económico-Social, No.29, Universidad Centroamericana, San Salvador, sepliembre-octubre 1992.

17. TOLEDO VIctor Manuel y otros, "Ecologla y autosuficiencia alimentaria", Siglo XXI Editores, México 1989.

18. Toledo, op. cit., p.22. 
de terreno para que la producción sea rentable...".19

EI MTE es buen reflejo de uno de los más grandes males en que basa su reproducción el sistema capitalisla: su tendencia a la uniformidad de los productos, técnicas, valores, ideas, gustos... $\theta$ inclusive de la naluraleza. La "homogenización" de las actividades humanas que lleva a cabo el capitalismo moderno, con su mágia (pues esconde la complejidad de la vida y el pensamienlo) y su encanto (pues simplifica la vida cotidiana y el "quehacer espiritual" del ser humano), es, como diria Hegel, como la noche... "en la que todos los gatos son pardos". Y ahora que muchos pueblos del llamado Este europeo, hace poco bloqueados por la deformación totalitaria de sistemas no capilalistas, se dejan seducir por aquella mágia y encanto del sislema occidental de mercado, creemos pernitente exponer una de las conclusiones a las que llega el estudio de Toledo: "Existe entonces una contradicción aparentemente insalvable entre la naturaleza misma de la economía de mercado y la diversidad de los ecosistemas". ${ }^{20}$

\subsubsection{EI MTE y la producclón agroexportadora.}

Antes de penetrar en el análisis de la viabilidad y de los efeclos que el MTE ha tenido en la siluación ecológica de El Salvador es necesario conocer si lal modelo ha sido un rasgo del lipo de producción que lleva a cabo la agroexporlación.

En primer lugar, podemos percalarnos que la producción agroexportadora posee una de las principales características del MTE: el monocultivo. Basta dar un vistazo a las grandes plantaciones de algodón y cafa para darse cuenla de ello. Es más, estos cultivos han normaimente ocupado las tierras que se supone más aptas para la aplicación del MTE, es decir las pocas superticies planas del país, uno de los suelos más fértiles, zonas con acceso al agua y con ciclos climálicos más o menos marcados.

En la producción cafetalera lambién puede hablarse de monocultivo, pero hay que indicar que al interior de las fincas encontramos mayor diversidad biológica que en el caso del algodón y caña. Aunque hay que decir también que la diversidad no es lan amplia, y que se limila a algunos "palos de sombra". Además, esta limitada diversidad de cullivos está más en lunción de la protección de los cafetales mismos, o de la extracción de lefia, que de las necesidades alimenticias de las personas.

19. Ibid, p.36.

20. Ibid, p.59. 
EI MTE aplicado al cullivo del café en El Salvador se ha alejado asi de algunas experiencias que, como la de ciertos indígenas de las zollas templado-húmedas de México, han sabido combinar el cultivo del calé con el de vegelales; y con ello, el MTE en el café ha limitado las posibilidades de reconciliación del auloabaslecimiento alimenticio con la generación de divisas por la agricultura.

Por último, traigamos a colación el caso de la pesca en alta mar. Acá se puede hablar de "mono-pesca", ya que las aclividades de Agx., a pesar de la exislencia de una diversidad de especies comerciales marinas que podrian llegar a las 1000 , se han especializado prácticamente en una, es decir en la extracción del camarón.

En segundo lugar, otro de los rasgos comúnes del MTE y la Agx. es el predominio de los criterios técnicistas y produclivistas de producción. Ya hemos hecho alusión al proceso de "quimiquización" que acompana la dinámica agroexportadora. Cinámonos acá a detallar unas de sus mayores manifestaciones. a. Los incrementos en la produclividad del suelo se han basado en la aplicación intensiva y masiva de fertilizantes químicos: si en 1961 se aplicaban en el pais 126993 Ton. de abono y de ellas el $52 \%$ eran de origen inorgánico, para 1971 la casi dos veces superior cantidad de abonos (233255 Ton.) poseía un $76 \%$ de orígen inorgánico; las importaciones de fertilizantes pasaron de apenas 49 mil dólares en 1960/61, a más de 18 millones de dólares en 1974/75; si en la cosecha $72 / 73$ se aplicaban 130 Kilogramos de N, P2 O5 y K20 por Ha. (ya una de las más allas del continente según la FAO), en 1973/74 se habia incrementado a $166 \mathrm{Kgs}$. por Ha. Tómese en cuenta que los que concenIran el uso de fertilizantes son los cultivos de exportación. Sólo un pequeho porcentaje se emplea en otros cullivos como el arroz y irutas, sobre todo las de exportación. 2. El control de plagas se hace esencialmenle con pesticidas : el gasto en pesticidas en 1960 era de 16 millones de colones, de 18 millones en 1970 y de 55 millones en 1975; de 1970 a 1974 el consumo de pesticidas creció a un $16 \%$ anual. ${ }^{21}$; las mismas fuentes oficiales determinan que "Durante el periodo de 1965 hasta fines de la década de los años 70 , se utilizaron más pesticidas por unidad de área que en cualquier otra parte del mundo. El número de aplicaciones aéreas de DDT y otros hidrocarburos clorinados, alcanzó a 56 durante un espacio de tres meses".22 Como se verá, esle uso intensivo y masivo de

21. Todos los dalos han sido tomados de RUIZ GRANADINO Santiago, "Modernización agrícola en El Salvador", Revista ECA, Universidad Centroamericana, San Salvador, noviembre 1979.

22. EXPERTOS SALVADOREÑOS Y AID, op. cil., p.23. 
insumos químicos como técnica casi exclusiva de aumentar la productividad, condujo a otro rasgo del MTE: la deterioración de la relación insumo producto. En efecto, en El Salvador la tasa de crecimiento de insumos ha sido superior a la de la producción, de tal suerte que si en 1960 el valor de los insumos sólo representaba el $11 \%$ del valor de la producción, en 1975 era cercano al $21 \%$... "El valor generado por cada dólar de insumo disminuyó en el periodo de US \$3.80 en 1960 a US $\$ 1.92$ en 1975". ${ }^{23}$

En tercer lugar, una de las caraclerísticas, al tiempo que consecuencia del MTE, como es la especialización productiva, es similar a olro rasgo-electo de la dinámica agroexportadora, como es la polarización de la estructura agraria. Ambos procesos, de especialización y polarización, conducen a semejantes resultados en el caso salvadorefio: el especializar a un polo de explotaciones modernas en los cultivos comerciales de exporlación, y a otro polo mayoritario y no moderno en los cultivos básicos de subsistencia.

En tal sentido podemos afirmar que el MTE que porta la Agx. y que lleva a polarizar la estruclura agraria, se ha exlendido al polo produclor de granos básicos.

Esta expansión puede entenderse de dos maneras. La primera, desde el punto de vista de la reducción de la diversidad producliva y/o de la imposición del monocullivo al interior del polo de subsislencia. La segunda, desde el punto de vista de la imposición de los criterios produclivislas/lecnicistas y/o de los llamados "paquetes lecnológicos" dentro del mismo polo.

Aunque no disponemos de estudios e informaciones para hacer un análisis consistente sobre la primera forma de expansión del MTE (y no creemos que hayan muchos), hemos estimado conveniente hacer unos planteamientos al respecto, haciendo conciencia de su nivel teórico o hipotético. Así, una visión panorámica e histórica de los sistemas produclivos del campesino salvadorefío nos muestra una evolución lendiente a la reducción de su diversidad productiva. Tal pareciera que buena parte del campesino de antaño introducía el cultivo de fruta y verdura a su sislema productivo basado en granos básicos. Con el tiempo, gran parte de ellos, por razones poco investigadas, se vieron obligados a especializarse en el cultivo de granos. En fechas más recientes, los cullivos combinados de maíz y frijol y/o maicillo son menos frecuentes y es más común encontrar unidades campesinas donde sólo se cultiva el maiz. Con la profundización de la polarización agraria, la Agx. fue introduciendo en el campesinado salvadorefío uno de los pilares del MTE, el mono-

23. RUIZ Sanliago, op. cit., p.88. 
cullivo, destruyendo asi "el rasgo que caracteriza ecológicamente a toda economia campesina... la estrategia de uso múltiple".(TOLEDO. op. cit.).

La otra forma de expansión del MTE, esta vez a nivel general, es por medio de la penetración de los criterios y técnicas productivistas en el cultivo de los granos básicos, obviamente entre los medianos y grandes productores de los mismos. Es así que la mini-revolución verde que se aplicó sobre todo en la producción de granos en la década de los 70 , hizo girar los incrementos de producción en la utilización de semilla mejorada (y menos en el uso de fertilizantes). Como dirla S. Ruiz "El uso de semilla mejorada en los cultivos de granos básicos se difundió en la década de los setenta, llegando a representar en 1975 el $41 \%$ de la superficie cultivada; el cultivo del arroz se realiza en su totalidad con semilla mejorada; el maiz es cultivado en un $59 \%$ con semilla certificada... En el trijol solo el $20 \%$ se cultiva con nuevas variedades... y en el caso del maicillo no llega al $8 \% " .24$

El monocultivo y utilización inlensiva de insumos químicos como criterio fundamental para incrementar la producción que predomina dentro del sector agroexportador, así como la ampliación de los mismos al sector especializado en la producción de granos básicos, son elementos que muestran la vigencia y dominio del MTE deniro del agro salvadoreño ¿Es éste un modelo viable para las condiciones nalurales de EI Salvador? ¿Cuáles son las consecuencias de la aplicación del MTE para la situación ecológica del pais? Son estas las cuestiones que pretendemos responder en los dos puntos que siguen.

\subsubsection{La vlabllidad del MTE dentro del ecosistema de EI Salvador.}

A pesar que la disponibilidad informativa en este tipo de aspectos es tremendamente limitada, apoyados en algunos dalos y análisis dispersos, podemos arriesgarnos a responder que el tipo de ecosistema que posee EI Salvador no es adecuado para la implantación del MTE.

En primer lugar, el pluricullivo era uno de los rasgos de las antiguas culturas pre-colombinas que habilaron el pais: "Las sociedades precolombinas de México y de Centro América se alimentaban bien gracias a la domesticación y a la utilización de una vasta gama de especies vegetales locales de las que la mayor parte han sido dejadas de lado en el transcurso del proceso de occidentalización" .2s

En segundo lugar, el ecosistema que contiene el pais es propicio al

24. Ibid, p.80.

25. DOUGHERTY Y OTROS, op. cit, p.104. 
desarrollo de actividades agropecuarias múltiples. Uno de los trabajos ya mencionados hace la siguienle descripción geográlica: "Aunque desde el punto de vista ecológico, El Salvador se encuentra latitudinalmente dentro de la región "tropical", por sus condiciones de topografla y altitud, el país presenta una complejidad y diversidad de macro-climas, y de manera especial una amplia variedad de micro-climas, a pesar de la estrechez de su territorio". ${ }^{26}$ En el mismo esludio se destaca la variedad de suelos que posee El Salvador. Esta diversidad climálica, topográfica y pedologica es muy favorable al desarrollo de sistemas productivos agropecuarios diversos.

En tercer lugar, el ecosistema salvadoreno no presenta las condiciones topográficas adecuadas que requiere la puesta en marcha del MTE. En El Salvador "la mayor parte del territorio se distingue por una topografía escabrosa y quebrada, debido a recientes actividades volcánicas y tectónicas" ${ }^{27}$ Considérese que casi el $50 \%$ del país está compuesio por volcanes y montafias. Sólo una pequena franja de la planicie coslera (cerca del $10 \%$ del territorio), y una serie de valles dispersos, reúnen ciertas condiciones topográticas adecuadas al MTE. Es mas aún, en los fértiles suelos de la planicie costera se ha aplicado un MTE inadecuado, como es el que acompaña al cultivo del algodón. Ya se han hecho varios sef́alamientos agronómicos sobre la inconveniencia de desarrollar en aquellos suelos un tipo de planla que por sus débiles raíces, la ausencia de cubierta vegetativa y elevado uso de insumos químicos, es un cullivo desprotectivo que ha dafiado seriamente la tertilidad natural de los mismos.

A pesar que algunos rasgos del ecosistema salvadorefio ponen en entredicho la aplicabilidad del MTE, éste ha sido adoptado y dilundido por la dinámica agroexportadora. ¿Cuáles han sido los efeclos que ello ha producido en la siluación ecológica y alimentaria del país? Pasemos a analizarlo.

\subsubsection{El rol del MTE de la agroexportación en los desequillbrios ecológlcos de El Salvador.}

A un nivel general, y retomando las expresiones de Toledo (op. cit), el MTE produce la erosión del suelo y la baja de su fertilidad, la salinización y el agotamiento de las aguas subterráneas en las áreas de riego, la contaminación del medio ambiente a causa de la gran aplicación de insumos químicos, la pérdida de la diversidad genélica de las especies

26. EXPERTOS SALVADOREÑOS Y AID, op.cit., p.3.

27. Ibid, p.2. 
cultivadas, la mayor vulnerabilidad a plagas y enfermedades de los monocultivos extensos, y la tendencia a un superior uso de insumos energéticos no renovables, como el peiróleo y el gas nalural, y por ende el aumento de los costos energélicos.

Es más, uno de los pilares menos cuestionados del MTE, como son los fertilizantes, no parece tan adecuado en si mismo. Esto en razón de que, como lo anola Collins, eslos productos químicos que aumentan los rendimientos no contribuyen a conservar 0 incrementar los componentes orgánicos de la lierra. A la larga, ésto irá afectar los mismos rendimienlos del sistema productivo. Sobre el lema, y con la finura que caracterizan sus análisis, dicho autor advierte: "Depender antes que nada de los fertilizantes químicos puede conducir a la derrota a largo plazo. Mientras más se dependa de ellos y no del estiércol, los abonos orgánicos, la rotación de cultivos y el abono verde, más disminuirá la materia orgánica y las plantas serán menos capaces de absorver el nitrógeno inorgánico de los fentilizantes químicos. Esto nos ayuda a comprender por qué la agricultura de Estados Unidos, según el biologo Dr. Barry Commoner, utiliza ahora alrededor de cinco veces más fertilizantes que en 1947 para producir el mismo volúmen de cosechas". ${ }^{28}$

A nivel particular, las consecuencias negativas sobre la situación ecológica de EI Salvador, producidas por la aplicación del MTE en la Agx., o del proceso de polarización que ésta genera, se presentarian de la siguiente manera:

En el caso del cultivo del algodón. Este es el sistema produclivo que más dano ha causado al ecosistema salvadoreño. Su expansión se hizo a costa de la práclica eliminación de la cubierta lorestal, en detrimento de la diversidad biológica y del equilibrio ecológico que lo acompaña, del desplazamiento de buen número de explotaciones productoras de alimentos, de la contaminación de aguas continentales y mares junto con la desaparición de muchas especies acuáticas, de la contaminación de muchas especies de animales terrestres y aves y de la progresiva extinción de algunas de ellas, en contra de la salud y la vida de muchos trabajadores rurales y consumidores en general. Los perjuicios y dańos superan con creces los dudosos beneficios de la modernidad y progreso atribuidos al desarrollo del cultivo del algodón. Los coslos económicos que su impulso ha ocasionado al pais (muchos de ellos aún no calculados) han sido sin lugar a duda muy superiores al monto de unas divisas que en su mayor parte se dirigian a una pequefia minoria.

28. MOORE LAPPE Frances y COLLINS Joseph, Comer es primero. Más allá del mito de la escasez, Editorial Siglo XXI, México, 1986, p.150. 
La técnica del monocultivo llevada a cabo sin piedad en la producción del algodón ha incidido nocivamente en el equilibrio de algunos ecosistemas. He aquí dos ejemplos:

A. El suelo descubierto dejado por el cultivo del algodón y la debilidad Je las raices de éste (exponiendo al suelo más al sol, lluvias y vientos costeros) han provocado una pérdida de fertilidad del mismo, su erosión - su resecamiento. Esto a su vez ha exigido una mayor demanda de fertilizantes, alterado o disminuido los componentes orgánicos de la tierra, incrementado los coslos por insumos y elevado los montos de la importación. Por otro lado, aunque por falia de datos sólo quede como planteamiento hipolético, hay que considerar que la pérdida de húmedad del suelo podría haber provocado la salinización de la misma. No ha sido por todo ello casual que, después de cinco o seis anos del "boom" algodonero, y que comienza en 1954, la productividad del algodón en EI Salvador, una de las más allas del mundo en aquél enlonces, haya comenzado a disminuir paulatinamente. Ya desde mediados de los 60 la rentabilidad del algodón, más allá de la depresión de los niveles de precio, viene poniéndose en tela de juicio.

B. La práclica eliminación de la diversidad vegelal que acompaña el monocultivo del algodón ha conllevado también la reducción de la diversidad de las especies animales, en especial de los inseclos. Los desequilibrios en el ecosislema de los insectos ha favorecido el desarrollo de unas pocas especies, muchas de ellas nocivas, aumentando así los riesgos de aparición de nuevas plagas. Algo parecido ha ocurrido con la proliferación de roedores.

Por otro lado, la utilización masiva y generalizada de insumos quimicos como técnica privilegiada de la producción algodonera, ha sido otro elemento del MTE que ha desestabilizado enomemente los equilibrios del ecosistema. He aqui olros ejemplos:

A. Ya hemos sefialado que el tipo de aplicación de insumos inorgánicos que se ha llevado a cabo en el cultivo del algodón ha alterado el sano equilibrio entre los componentes del suelo.

B. La armonia existente entre el aire y la tierra parece verse también modificada. Esto es posible si tomamos en cuenta que ante la pérdida de efectividad de ciertos insumos quimicos, las explotaciones algodoneras en El Salvador comenzaron a utilizar desde hace más de diez anos insumos lostalados (como el malation y el paration). Ahora bien, resulta que la aplicación de insumos químicos fostalados, cuando son aplicados en suelos tropicales ricos en aluminio, como son en buena parte los de la zona algodonera, no son sólo inútiles sino que también dañinos por sus 
emanaciones de gases tóxicos.

C. El uso abusivo de insumos químicos en el cultivo del algodón, y en los de la Agx. en general, ha conducido al desarrollo de dos tipos de círculo vicioso, uno de orden ecológico y el olro de orden económico. El primero se planlearia asi: a más plaguicidas mayores plagas (por la resistencia genélica de algunos inseclos y la desaparición de sus depredadores nalurales, que lleva a la prolileración de los primeros), y a mayores plagas más y más fuerles plaguicidas (por una cultura modernista $e$ intereses económicos que no abren campo a otras técnicas de control de plagas). El segundo círculo tendria la siguiente expresión: a mayores actividades de la Agx., más necesidad de importar insumos y por ende de divisas, y a mayores necesidades de divisas, más necesidad de impulsar las actividades agroexporladoras.

D. Afradamos que la extinción o amenaza de extinción de ruuchas especies animales por causa de intoxicación, y los desequilibrios ecológicos que ello provoca, están intimamente ligados a este rasgo del MTE en el cultivo del algodón.

E. La técnica de riego automático por aspersión, practicada con trecuencia en muchos algodonales, y lambién en cafiaverales, ha exigido la desaparición de los bosques y/o otras planlas de allura.

Nuevamente nos encontramos con una serie de factores ecológicos perturbados que van en contra de las capacidades productivas y disponibilidades alimentarias calificadas: suelos alterados y degradados; agua, tierra y aire contaminados; expansión de plagas; incremento de importaciones y potenciación de los cultivos no alimenticios de exportación (que en las condiciones especificas de El Salvador ha significado lambién el debilitamiento de los produclores de granos básicos).

En el caso de la pesca de exportación y en el de los productos más afectados por la polarización de la estructura agraria producida por la dinámica agroexporadora: el camarón y los granos básicos. En la producción de estos productos (seleccionados en base a las informaciones disponibles) también se ha aplicado o padecido, en diversa medida y nivel, el MTE. Veamos algunas de sus consecuencias ecológicas.

El tipo de producción llevado a cabo por la pesca del camarón ha traído también sus costos ecológicos:

A. La pesca especializada del camarón atenta contra la reproducción a medio plazo de esta especie.

B. La pesca indiscriminada por medio de la técnica de captura masiva en grandés atarrayas, ha arrastrado consigo la muerte de mucha fauna 
de acompanamiento (pescado de escamas sobre todo), entre las cuales se implican muchas especies poco desamolladas u otras en estado de gestación. Esta pérdida importante de la diversidad biológica se anade a la del camarón, perlurbándose asi seriamente los equilibrios necesarios entre la fauna marina.

C. La especialización se hace acorde a crilerios comerciales corto placistas, por lo que no se toma en cuenta el allo costo energético que implica la pesca del camarón : si para oblener una kilocalorla de proteina de Anchoveta, Perca, Bacalao o Atún, se necesitaban 2, 4, 20 y 20 kilocalorias de energía tósil respectivamente, para oblener una de camarón se requerian entre 150 y 206 de energía. ${ }^{20}$

Todos estos factores mencionados no resultan extrafios a algunos de los dalos que mencionábarnos anteriormente: desde 1964 la pesca del camarón ha disminuido en más de la mitad; entre 1963 y 1972 el consumo de diesel por unidad de embarcación se dobló, y el número de naves camaroneras y los dias de pesca se incrementaron en un $11 \%$.

En lo que se refiere a los cullivos más alectados por la "polarización agroexportadora" podemos exponer varias consecuencias negativas. La tendencia al desarrollo del monocultivo al inlerior de los granos básicos, impulsado por el proceso de polarización que genera la dinámica agroexportadora, trae aparejado fenómenos semejantes a los presentados en el cultivo del algodón: la disminución de los cultivos combinados de maiz y frijol no contribuye a la fertilidad del suelo, ya que se desaprovecha el intercambio equilibrado de nutrientes que produce la allernacia de ambas plantas (la planta del maíz consume mucho nitrógeno mientras que la del frijol conlribuye a fijarlo en el suelo); menos diversidad de plantas signitica menos diversidad de insectos y más posibilidad de desarrollo de plagas; el monocultivo "ha propiciado la siembra contínua de cultivos "abiertos", como el maíz, que exponen el suelo a la erosión...".30

La utilización de semillas mejoradas que ha impulsado el MTE dentro de la producción de granos básicos no es menos inocente. Y esto no tanto porque produzca alteraciones perjudiciales al medio ambiente como por sus electos socio-económicos sobre la situación alimentaria. Como to analiza Collins, las semillas mejoradas o las variedades de "allo grado de respuesta" requieren para su aprovechamiento una serie de condiciones que normalmente no eslán al alcance de los pequefios productores de granos básicos: acceso al agua o dolación de infraestructura para la canalización o drenaje de la misma (dada la mayor sensibilidad de ese tipo de

29. TOLEDO, op. cit., p.51.

30. LAPPE y COLLINS, op. cit., p.224. 
semillas a las inundaciones o sequias), mayores recursos para el control de plagas o enfermedades (debido a la menor resislencia a éslas por parte dt las semillas mejoradas), acceso a las redes inslitucionales que suelen manejar su distribución, mayores conocimientos agronómicos, etc. En consonancia con lo anterior, la difusión de semillas mejoradas entre los productores de granos básicos, en ciertas condiciones, incrementa los costos de producción, aumenta la dependencia y la deuda de muchas explotaciones, arnina a otras, e incrementa las desiguladades socio-económicas entre los productores de granos. Todo eslo se traduce de manera desfavorable en la situación ecológica (por los efectos nocivos de la pobreza sobre el medio ambiente) y alimenticia del pals.

Valga advertir sin embargo, como veremos más adelante, que los problemas ecológicos derivados del lipo de producción que caracterizan los granos básicos no provienen lanto de la aplicación del MTE y/o de la modernización como de una de sus consecuencias más importanles: la pobreza.

En sintesis, el predominio del MTE en algunos sistemas productivos de los productos agrícolas o pesqueros de exportación, asi como su aplicación en la producción de granos básicos, en buena parte debida al proceso de polarización que la Agx. engendra, son circunslancias que han contribuido a empeorar la precaria situación ecológica de El Salvador.

\subsection{El tlpo de tenencla y uso del suelo.}

La dinámica agroexportadora ha desarrollado un tipo de tenencia y uso del suelo que contribuyen también a explicar los graves problemas ecologicos que ha padecido El Salvador.

i. Como es sabido, la mayor parte de las explotaciones agroexportadoras se encuentran en régimen de "propiedad" (en menor medida en el cultivo del algodón), mientras que la mayorla de las pequefias unidades productoras de granos básicos se vieron conminadas al régimen de "arrendamiento simple" (sin promesa de venta): "La importancia de las diferentes formas de tenencia está directamente relacionada con el tamano de las fincas. En todos los paises (de Centro América se entiende. N. del A.) existe la tendencia a que las formas más alejadas de la propiedad se concentren en los grupos de fincas de menor tamaño. Por ejemplo... en El Salvador más del $98 \%$ de las fincas en arrendamiento simple se encuentran también dentro de los grupos de microfincas $y$ subfamiliares". ${ }^{31}$ Por otro lado, según las inlormaciones de los únicos tres

31. CEPAL, FAO, OIT, Tenencia de la tierra y desarrollo rural en Centroamérica, EDUCA Editores, San José. Cosla Rica, 1973, p.83 y 85. 
Censos Agropecuarios habidos en el país $(1951,1961$ y 1971) la folma de tenencia que tuvo el mayor crecimiento fue la del arrendamiento simple : en el lapso del 51 al 71 el número de explotaciones en arriendo aumentaron en un $144 \%$ y la superticie bajo esla forma de lenencia to hizo en un $106 \%$. De tal forma que si en 1961 solo el $19 \%$ del tolal de las explotaciones y el $4.9 \%$ de la superficie global en lincas eslaba bajo arriendo simple, en 1971 esta forma de lenencia abarcaba el $28.1 \%$ de las explotaciones y el $7.2 \%$ de la superficie.

Por tanto, las formas de tenencia en arrendamiento simple se han extendido especialmente entre los pequenos productores de alimentos. ¿Qué implicaciones tiene esto para la situación ecológica?

Las formas de arrendamiento simple son las menos adecuadas para motivar a sus usuarios a la inversión, sobre todo en materia de preservación de los recursos... en especial para los pobres productores de alimentos que no tienen mucho qué invertir. Menos inversiones significa, en este caso, menos capacidad para producir alimentos. El caso de un país asiático nos ilustra sobre el tema. En Bangladesh, un serio problema para los agricultores son las fuertes lluvias que se presentan durante tres o cualro meses al ańo y la necesidad de controlar el agua para evilar los excesos o para aprovecharla en el largo periodo de sequia. Ahora bien, "Los aparceros y los jornaleros, sin embargo, carecen de todo incentivo para construir y conservar canales de drenaje, irrigación y bordos, puesto que saben que tales inversiones beneficiarán casi exclusivamente a los terratenientes. Además, los pequeños propietarios piensan, con toda razón, que cualquier mejoria en la tierra puede aumentar el deseo de los terratenientes de apoderarse de ella" ${ }^{32}$ De la misma forma, la tenencia de la tierra bajo arrendamiento simple no estimula la inversión necesaria en la conservación y/o mantenimiento del ecosistema ¿Cómo puede ponerse a pensar un campesino en incremenlar una cubierta forestal que podría lomar de 5 a 15 años cuando sus expeclalivas de posesión no superan el año?

ii. La fuerza integradora y articuladora de la Agx. ha marcado prolundamente el tipo de uso dado al suelo. Nos referiremos al uso adecuado o inadecuado de la tierra tomando en cuenta la vocación y calidad agronómica de ésta. En primer término, si partimos de la vocación agropecuaria de los suelos, podremos percatarnos que la dinámica agroexportadora ha desembocado en una ulilización inadecuada de los mismos.

A un nivel general se podria hablar de una sobreutilización de la tierra con lines agrícolas y pecuarios: si en 1975 la lierra con polencial o

32. LAPPE y COLLINS, op. cit., p.32. 
vocación agricola del pais era de unas 515 mil Ha., realmente se cullivaban 623 mil $\mathrm{Ha}$., o sea un sobreuso cercano al $21 \%$ del polencial; las lierras con vocación ganadera eran de unas 450 mil Ha., pero efectivamente se trabajaban 465 mil Ha., es decir un ligero sobreuso de poco más del $3 \%$. Mientras que se podría hablar de intrautilización de la tierra cuando hablamos de los suelos de vocación lorestal : si éstos comprendian una extensión de 600 mil Ha. apenas se usaban $184 \mathrm{mil} \mathrm{Ha}$. con tales fines, b que significa un infrauso de aproximadamente $31 \%$ del polencial. ${ }^{33}$

$A$ un nivel particular, podremos seguir afirmando el tipo inadecuado que se le ha otorgado al suelo en El Salvador, aunque los análisis se pueden invertir o complicar. En primer lugar, cuando hablamos de sobreuso de la tierra con tines agrícolas hay que pensar más bien en la pequena que en la gran empresa. Eslo resulta plausible cuando constalamos que, según dalos de CEPAL, FAO OIT para $1971^{34}$, mientras la gran explolación destina sólo un $29 \%$ de su propiedad a cultivos agricolas la micro-empresa destina el $92 \%$; eslo podria sugerirnos una infrautilización de la tierra con vocación agrícola dentro de las grandes unidades (además del sobreuso en las pequehas). En segundo lugar, al referirnos al sobreuso de las lierras con potencial ganadero, hay que volver los ojos más hacia las grandes propiedades que a las pequefias: éslas sólo ocupaban un $6 \%$ de sus suelos con fines ganaderos, en tanto que las mullifamiliares grandes usaban casi la milad de sus propiedades para tales fines; datos que en cierta medida y circunstancias apuntarian también hacia una especie de "infraulilización" de la tierra con vocación pecuaria en el caso de las economias campesinas ( $y$ el sobreuso en las grandes).

Oro uso inadecuado de la tierra provenia del hecho que las grandes explolaciones mantenian como promedio más del $30 \%$ de sus propiedades práclicamente sin ninguna actividad o finalidad producliva, en lanto que las pequeñas implicaban en ello a más del $96 \%$ de su propiedad.

En conclusión, la inadecuación del suelo provocada por la Agx., no sólo se da en términos de la comparación general del uso actual con el

33. Los datos ha sido extraidos de RUIZ S, op. cit., p.74. Hay que advertir sin embargo que este autor parece no considerar los suelos con "uso restringidon dentro del total del uso polencial. Si introducimos este tipo de tierras con polencial restringido no podríamos hablar de sobreutilización de la tierra, ya que las mismas superan las $300 \mathrm{mil} \mathrm{Ha.(MONTES} \mathrm{S,} \mathrm{op.} \mathrm{cil.,} \mathrm{p.117).} \mathrm{Pero} \mathrm{no}$ se modificaría nuestra tesis sobre la inadecuación del uso del suelo: se trataria de un uso inadecuado o excesivo respecto al potencial de las tierras cuyo uso no presenta restricciones.

34. CEPAL, FAO, OIT, op. cil., cuadro C-7. 
uso polencial de los suelos, sino también con la sobreutilización o infrautilización que en si mismo hacen del suelo las pequefias o grandes explotaciones agropecuarias. Los desequilibrios entre el uso real y potencial de los suelos, los excesos de ulilización de la tierra en las pequehas explotaciones o el uso deficiente en las grandes, son todos ellos aspectos que irán a reperculir o repercuten negativamenle en la preservación de los equilibrios del ecosistema del pais.

iii. La inadecuación en el uso del suelo se muestra también cuando tomamos en cuenta la calidad del mismo. Como ya to hemos senalado, las tierras de mejor calidad han estado en manos de las grandes y mejor dotadas empresas agricolas productoras de bienes no alimenticios de consumo inlerno, mientras que las más pequehas y de menos recursos, productoras de alimenlos básicos, se ubican en las peores tierras. Una visión panorámica del lerritorio nacional mostraria las montanas escarpadas y erosionadas del norte del pais, a las poco fértiles y también erosionadas montańas costeras, y a muchas laderas y cerros de la llamada cadena volcánica antigua de la región central (mucho menos lértil que la volcánica reciente), como los lugares de poblamiento de miles de productores especilizados en el cultivo de granos básicos. Al otro lado del "mirador" percibiamos a una minoria de propietarios, llegando con sus avionelas los fines de semana a sus grandes explolaciones algodoneras, ubicadas en las que fueran las más ricas y lértiles tierras del país; 0 a los empresarios cafieros aproximándose en sus "cherokees" a los también nutritivos suelos de los valles centrales; 0 a los grandes cafetaleros subir con sus vehiculos "lodo lerreno" las fértiles propiedades que poseen en la cadena volcánica reciente.

Esa distribución geográfica de la desigualdad socio-económica, esa "injusticia geogrática" de la acumulación agroexporadora, ha sido injusta con los equilibrios de la naturaleza: porque son precisamente los que lienen los menores recursos para invertir en la conservación o protección de suelos los que se encuentran en las exlensiones con mayor grado y riesgo de erosión; porque son los produclores con más vocación agrícola, los que se ven empujados a las tierras que justamente poseen menor vocación agrícola; porque son exactamenle los suelos más necesitados de bosque o de cubierla vegetal, los que reciben el monocullivo abierto de los cereales. Por todo ello no es de extranar que las mismas fuentes oficiales afirmen que "Debido a que aproximadamente el $85 \%$ de 105 granos básicos proviene de tierras situadas en las zonas más escarpadas del pais, la erosión provocada por estos cultivos alcanza valores estimados en 500/ton/ $\mathrm{Ha} / a n o^{\prime \prime} .{ }^{35}$

35. EXPERTOS SALVADOREÑOS Y AID, op. cit., p.92. 
En síntesis, el funcionamiento y expansión que llevan a cabo las actividades agroexportadoras, aplicando o estimulando el MTE, haciendo evolucionar inestables formas de tenencia entre los pequenos productores de alimentos, relegando a éstos a las peores lierras y favoreciendo un uso inadecuado del suelo, se convirtió, quizá, en una de las principales causas del grave delerioro ecológico que ha experimentado EI Salvador en los últimos años.

\section{Factores explicativos que surgen del estlio de desarrollo que predomina en EI Salvador.}

Sin ánimo de ser exhaustivos, hemos escogido algunos rasgos del estilo de desarrollo que ha predominado en El Salvador que son causales importantes del estado endémico que presenta la siluación ecológica del país. Se Irata de rasgos que vienen en gran medida delerminados por la "fuerza dinamizadora y articuladora" que las aclividades de agroexporlación han tenido sobre el desarrollo de la sociedad salvadorena. ${ }^{36}$ Estos son: A. La masificación de la pobreza. B. Una serie de rasgos políticos-económicos e institucionales del estilo de desarrollo y que se refieren a la política agraria gubernamental.

\subsection{La masiflcación de la pobreza.}

La masificación de la pobreza, (el alto porcentaje de salvadoreños que viven en un estado de pobreza absoluta y relativa), es un destacado factor explicativo de los agudos desequilibrios del ecosistema. Las incidencias de lal fenómeno sobre esta última situación se fueron revelando en el transcurso de las páginas anleriores, aunque la relación entre pobreza y ecología no es quizá lan evidente. Extendamonos por tanto un poco más en su análisis.

He aqui algunos ejemplos que iluslran cómo la profunda pobreza de la mayoria de salvadorefíos es una variable importanle más que explica la pobre siluación de su ecosistema:

i. Una gran parte de la detorestación ocurrida en El Salvador ha tenido su origen en la lala de árboles, cuyo lin es la salisfacción de una

36. Los rasgos del estilo de desarrollo que ha predominado en El Salvador, y que en otro trabajo hemos denominado Estilo de Desarrollo Agroexportador, asi como el importante rol que las actividades agroexporladoras juegan en la configuración de dicho estilo, aparecen delallados y analizados en el documento que ha servido de relerencia a la elaboración de la presente investigación. Ver RUBIO Roberio, op. cit., especialmente el capítulo tercero. 
casi masiva demanda de lena. En efecto, la lena es la principal fuente de producción y consumo de energia en El Salvador: en 1978 representaba el $64 \%$ de los recursos energéticos locales, casi el $35 \%$ del total de la energia que se consumía en el pais y el $88 \%$ de la energla consumida en los hogares; otras fuentes olorgan al consumo de lena un $69 \%$ del consumo global en 1970 y un $64 \%$ en $1981 .{ }^{37}$ Además, su utilización ha sido creciente: entre 1970 y 1981 el consumo de lena a nivel nacional se incrementó a una tasa de crecimiento acumulativa anual del $2.8 \%$; el consumo de lefia de 1950 se dobló para 1978.

Ahora bien, dentro de esa gran olerta/demanda de lefia suceden tres cosas.

La primera es que un gran porcentaje de ella, es decir de un porcentaje de los 4 millones de Ton. en 1980, se producia/satisfacia a través de la lala incontrolada de bosque o árboles primarios (cerca de 1.2 millones de Ton. se extraian de esta manera y el reslo de las podas de árboles de sombra en los cafetales o de los bosques secundarios; aunque la poda de cafelales ha ido perdiendo imporlancia en la olerla de lefa, pasando de un $38 \%$ en 1970 a un $29 \%$ en 1980 ).

La segunda es que la mayor parle de esa oferta o demanda tenía un destino doméslico (cerca del $90 \%$ ).

La tercera es que quienes llevaban a cabo la tala incontrolada de árboles con fines domésticos eran fundamenlalmenle los pobres del campo. Esto se vuelve comprensible juslamente por las condiciones de marginalidad y pobreza en que vive la casi lotalidad de las familias rurales: más del $90 \%$ de la población rural carece de energia eléctrica; aunque tuvieran la infraestruclura disponible, los exiguos ingresos de los campesinos no les permitirian comprarla ni buscar otras fuentes alternativas de energía... sobre todo cuando la obtención de lefía es gralis. A la pobreza rural no parece habérsele dejado otro remedio para cocinar sus alimentos y satisfacer sus otras necesidades de energia: deforestar.

ii. Por olro lado, la deforestación y la pobreza se juntan para producir otro desequilibrio ecológico, esla vez respecto a las especies animales: la deloreslación conduce a la pérdida de la diversidad de especies animales y/o a su exlinción, mientras que la masilicación de la pobreza,

37. Las primeras cifras sobre producción y consumo provienen de DOUGHERTY y OTROS, op. cit., p.97. Los mayores porcentajes en el consumo de leña son dados por EXPERTOS SALVADOREÑOS Y AID, op. cil., p.108. Es posible que la amplia falta de coincidencia en las cifras de consumo de ambas fuentes obedezca a que en la primera de ellas se considere solamente la energía comercial. 
incentivando la búsqueda de otras fuentes alimenticias, favorece el aumento indiscriminado de la caza o la pesca, y con ello también la merma de la diversidad de las especies o su extinción.

iii. Otro efecto ecológico de la pobreza atane el uso de los suelos. EI empeoramiento de la situación económica, el crecimiento demográlico (y la parcelización que se desprende de las herencias de tierras entre los campesinos), las mayores inseguridades en las formas de tenencia, son algunos de los factores que llevan a modificar los patrones de uso del suelo o el paso gradual de los cultivos permanentes (como frutales) hacia los cultivos anuales (como los cereales). Ahora bien, la mayor actividad sobre los suelos que implica este úllimo tipo de cultivo impide la formación de la vegelación de acompanamiento y/o de bosques secundarios, y puede llevar a facilitar la erosión de los suelos.

iv. Todo lo recién dicho nos sugiere la existencia de un verdadero "círculo vicioso de la ecología de la pobreza" (como creemos que exisle uno de la ecología de la riqueza). Un círculo en el cual se implicarian al menos dos ciclos. Un ciclo podría iniciarse con la deforestación y se podría expresar en los siguientes lérminos: deloreslación -incremento de la erosión y menor diversidad genélica de las especies- menor productividad de la tierra y menor disponibilidad alimenlicia -aumento de la pobreza - mayor delorestación. El otro ciclo, de semejanle conlenido. podria iniciarse y terminarse con la pobreza misma: pobreza -incremento de la deforestación y/o de la erosión del suelo- disminución en la productividad de la tierra o en la diversidad genélica de las especiesmayor crecimiento de la pobreza.

\subsection{La politica gubernamental y la situación ecológlca.}

La política socio-económica de la casi totalidad de gobiernos que ha tenido la República de El Salvador no ha sido en general favorable para el mantenimiento de los equilibrios del ecosislema. Todo lo contrario, dentro del estilo de desarrollo predominante se han gestado políticas que, en términos globales, se han convertido en otro faclor explicalivo del mal-desarrollo que marca el pais.

En esle úllimo punto del Irabajo nos limilaremos a una exposición muy general que muestra cómo la política gubernamental, como parle del estilo de desarrollo agroexportador que caracterizó el país antes de 1980. se constiluyó en otro factor del delerioro ecológico. Evidentemente no se trata de un análisis de impacto de loda la política socio-económica que predominó en las fechas estudiadas; esto rebasaría con creces los 
propósitos de este punto. Simplemente queremos limitarnos al análisis de la politica gubemamental en lo que se refiere a ciertas "omisiones" frente a la problemática ecológica, asi como a algunas "acciones" o proyectos gubemamentales que se realizaron en décadas recién pasadas.

i. En primer lugar, la actitud gubernamental frente al problema ecologico fue de casi total apatía y negligencia. He aqul algunas muesIras:

A. El Patrimonio Nalural no fue un aspecto considerado en la Conslilución Política sino hasla en Diciembre de 1983.

B. El Salvador, donde el problema de la extinción de especies es uno de los más alarmantes del mundo, es uno de los tres paises latinoamericanos que, al menos hasta 1984, no habian firmado el importante documento de la Convención Internacional para el Comercio de Especies en Vlas de Extinción.

C. Hay casi una total ausencia de control gubemamental en la cacerla y la pesca; no existen tampoco períodos de veda en tales actividades. La falta de control es tan fuerte que incluso en las mismas zonas de propiedad gubernamental se daña seriamente el ecosistema. Los manglares es un ejemplo: la mayor parte son de propiedad y adminisıración estatal, sin embargo, como lo aceptan las mismas luentes oficiales, varios faclores "han conducido a que este "manejo y protección" se limite virtualmente a permitir una destrucción más lenta (y autorizada) del bosque". 30

Es cierto que la actilud gubernamental tropieza con un ordenamiento legal que adolece de problemas de insuficiencia, caducidad, dispersión, etc., y con gran escasez de recursos humanos para su aplicación (por ejemplo el Servicio Forestal sólo disponia en 1975 de un ingeniero y dos perítos forestales, y de los 91 profesionales universilarios, no universitarios o estudiantes que Irabajaban en él sólo 15 tenían algún lipo de enIrenamiento foreslal)..$^{39}$ Pero el problema nuevamente no es lanto de recursos como de voluntad política, un problema de la estructura de poder. Por ejemplo, la voluntad política de un gobierno "hambriento" de divisas y fuertemente controlado por oligárcas y militares, y la presencia signilicativa de algunos de éstos en la industria camaronera, son elementos que bloquearon todo serio intento de diversilicar y reglamentar la captura del camarón o de prohibir su carácter indiscriminado. Incluso cuando hay leyes, éstas no se aplican. Sobre eslo lo mejor es ir a las mismas luentes

38. EXPERTOS SALVADORENNOS Y AID, op. cit., p.85.

39. Ibid., p.199. 
oficiales: "En cuanto a los decretos de las Zonas Protectoras del Suolo, puede afirmarse que por la falta de decisiones politicas para su aplicación, éstos no han tenido los electos previstos. Tanto en la región metropolitana de San Salvador, como en la zona norte del país que es donde más deberian aplicarse, las condiciones de los recursos naturales permanecen en igual o peor situación que antes que los decretos tueran formulados". Los resultados a los que llego el único Plan Quinquenal de Gobierno que inclula la preocupación ecológica, el Plan "Bienestar para Todos" del 78 al 82, fue una prueba fehaciente de lo acabamos de afirmar.

ii. En segundo lugar, los desequilibrios del ecosistema no sólo se permiten por la actitud pasiva de gobierno, sino que también se originan en sus propias acciones o proyectos. Otra cita de procedencia oficial nos sirve para llustrar el tema: "No es extrano encontrar que en El Salvador se haya ejecutado o se programen grandes proyectos financiados por organismos mundiales, sin los respectivos estudios del impacto ambiental.."." Las mismas luentes oficiales van aún más lejos al reconocer parte de los contenidos polílico-económicos que subyacen dentro de los proyectos y acciones gubernamentales que alectan el ecosislema: "Las acciones del gobierno han reflejado más los motivos polfticos y las demandas de un pequeno pero fuerte sector, para mantener intacto el sistema de tenencia y uso de la tierra; la aplicación de estilos de desarrollo de otros palses no apropiados para el mejoramiento y bienestar del pueblo; el deseo de desarrollarse utilizando tecnologias extranjeras y sofisticadas no aptas para ecosistemas tropicales.." "2

La polltica socio-económica del estado salvadoreno no sólo sometió a la economla campesina a la racionalidad de la rentabilidad del capital agroexportador sino también a la naturaleza misma. No es casual entonces que las grandes obras y proyectos gubernamemtales hayan sido unos de los principales causantes del deterioro ecológico que sufre actualmente el pais.

Las grandes obras y proyecto de goblerno que se impulsaron durante la década de los 70 , y que tenían como una de sus principales finalidades hacer "atractivo" al pals a la inversion extranjera, nos patentizan el rol desequilibrador del ecosislema del que ha hecho gala la política gubernamental. He aqul algunos ejemplos, reconocidos posteriormente por inslancias oficiales preocupadas por los temas medioambientales:

40. Ibid., p.198.

41. Ibid., p.209.

42. Ibid., p.9. 
A. Un primer ejemplo de lo anlerior fue la construcción del Aeropuerto "Cuscallán". Dichas instancias dijeron al respecto que "se han comenzado grandes trabajos de emplazamiento de un nuevo aeropuerto de categoría A sobre la costa y la construcción de una gran autonuta que conectará el aeropuerto a la capital. Este proyecto ha sido elaborado sin ninguna preocupación por las repercusiones ecológicas y sociales a corto y a largo plazo sobre una región socialmento agitada y ecolbgicamente degradada".4

B. Otro gran proyecto de gobierno fue el desarrollo turistico de la cosla oriental, que contemplaba la construcción de una cadena de grandes holeles y la proliferación de ranchos privados de playa. La puesta en marcha de este complejo turístico cercano al aeropuerto, es decir en una de las regiones más afectadas en los equilibrios del ecosistema, fue llevando, según reconocía la misma empresa consultora del proyecto, a un cambio acelerado en "los esquemas de uso de la tierra a lo largo de toda la zona costera"; ello además de lodos los problemas de contaminación de manglares y de los derivados del tratamienlo de aguas negras.

C. Las restringidas y casi exóticas reservas ecológicas que le quedaban al lerritorio nacional tampoco se escaparon de la vorágine de los "modernos proyectos de desarrollo". Con el fin de atraer el turismo nacional (?) y extranjero se ulilizaron varias manzanas del tan preciado Parque Nacional Deniger para crear las inslalaciones de una pista de coches de carrera.

D. Muchas cosas habria que decir sobre la construcción del embalse del Cerrón Grande, uno de cuyos objetivos era reducir los coslos de energia eléctrica para alraer los inversores externos. A pesar del debale que se abrió en la época y los senalamientos que se hicieron sobre su conveniencia (entre otros sus repercusiones ecológicas) el proyecto se llevó a cabo. Las modificaciones en el clima, la evaporación y erosión del suelo, la composición de las especies, etc., de las también degradadas condiciones ecológicas de la zona norte, no parecen ser ajenos a los "magnificos progresos" de la modernidad oficial.

Una recapitulación de lo dicho en esle documento nos lleva a asegurar que las mismas caracteristicas del estilo de desarrollo agroexportador y las políticas socio-económicas que lo acompanan, han sido olras de las causas del mal-desarrollo ecológico de un país que con orgullo se ha

43. DOUGHERTY Y OTROS, op. cil., p.106. 
autodenominado (o nominado) "el pulgarclto de América". Las conclusiones a las que hemos llegado anaden otros motivos que justifican ese sobrenombre más allá de la pequenez territorial, y que no son porladoras de orgullo: enorme reducción o disminución de su "talla" ecológica.

\section{BIBLIOGRAFIA}

ALVARADO José Antonio, "Factores generadores y propagadores de la crisis filscal", Revista Realidad Económico-Social, Ne 3 Departamento de Economla, Universidad Centroamericana, San Salvador, Mayo-Junio 1988.

BRIONES, CARLOS, "Reàlidad y perspectiva de la pobreza en EI Salvador". Boletin de ciencias econdmicas y sociales No. 6, Noviembre-Diciembre 1987.

CEPAL, FAO, OIT, Tenencia de la tierra y desarrollo rural en Centroamérica, EDUCA Editores, San José, Costa Rica, 1973.

DOUGHERTY H.E., JEANNERET C.A. y FLETCHER H.F., Stratégies d'ecodeveloppement pour le Salvador, Documento fotocopiado, Ginebra, 1979.

EL SALVADOR PROCESO, "Código de salud: nueva conírontación entre gobierno y sector privado", Informativo semanal del Centro Universitario de Documentación e Información, UCA, No. 332, Sen Salvador, abril 1988.

MONTES, Segundo, El agro salvadoreño 1973-80. UCA Editores, San Salvador, El Salvador, 1986.

PROGRAMA CENTROAMERICANO DE CIENCIAS SOCIALES, CSUCA, Estructura agraria, dinámica do población y desarrollo capitalista en CentroamérC8, EDUCA Editores, San Joś, Costa Rica, 1978.

RUEIO ROEERTO, El rol de la agroexportación en la conformación de la situación allmentaria y ecológica de El Salvador 1950-1979, Tesis Doctoral, Louvain-la-Neuve, Bélgica, 1991.

RUIZ GRANADINO Santiago, "Modernización agricola en EI Salvador", Documento totocopiado de Revista ECA, Universidad Centroamericana, 1979.

TOLEDO VIctor Manuel y otros, Ecologla y autosuticiencia alimentaria., Siglo XXI Editores, Móxico, 1989.

VARIOS EXPEATOS SALVADORENOOS Y AGENCIA PARA EL DESARROLLO INTERNACIONAL DE LOS ESTADOS UNIDOS DE AMERICA, Pertil Ambiental de El Salvador, U.S.A.D.I., Contrato No 519-0167-C-00-2039-00, San Salvador, El Salvador, Abril de 1985. 